\title{
Early life exposure to air pollution and incidence of childhood asthma, allergic rhinitis and eczema
}

\author{
Teresa To ${ }^{1,2,3}$, Jingqin Zhu ${ }^{1,3}$, Dave Stieb ${ }^{4}$, Natasha Gray ${ }^{1}$, Ivy Fong (1) ${ }^{1}$, \\ Lauren Pinault ${ }^{5}$, Michael Jerrett $^{6}$, Alain Robichaud ${ }^{7}$, Richard Ménard ${ }^{7}$, \\ Aaron van Donkelaar ${ }^{8,9}$, Randall V. Martin (10,9,10, Perry Hystad ${ }^{11}$, \\ Jeffrey R. Brook ${ }^{2}$ and Sharon Dell ${ }^{1,2}$
}

\begin{abstract}
Affiliations: ${ }^{1}$ Child Health Evaluative Sciences, Research Institute, The Hospital for Sick Children, Toronto, ON Canada. ${ }^{2}$ Dalla Lana School of Public Health, University of Toronto, Toronto, ON, Canada. Institute for Clinical Evaluative Sciences, Toronto, ON, Canada. "Environmental Health Science and Research Bureau, Health Canada, Ottawa, ON, Canada. ${ }^{5}$ Analytical Studies Branch, Statistics Canada, Ottawa, ON, Canada. ${ }^{6}$ Fielding School of Public Health, The University of California, Los Angeles, CA, USA. Air Quality Research Division, Environment and Climate Change Canada, Dorval, QC, Canada. ${ }^{8}$ Dept of Physics and Atmospheric Science, Dalhousie University, Halifax, NS, Canada. ${ }^{9}$ Dept of Energy, Environmental and Chemical Engineering, Washington University in St Louis, St Louis, MO, USA. ${ }^{10}$ Harvard-Smithsonian Center for Astrophysics, Cambridge, MA, USA. ${ }^{11}$ College of Public Health and Human Sciences, Oregon State University, Corvallis, OR, USA.
\end{abstract}

Correspondence: Teresa To, Child Health Evaluative Sciences, The Hospital for Sick Children, 686 Bay Street, Toronto, ON M5G 0A4, Canada. E-mail: teresa.todsickkids.ca

@ERSpublications

This study found that exposure to total oxidants at birth increased the risk of developing asthma by $17 \%$ and eczema by $7 \%$. Adverse impacts of exposure to air pollutants, particularly ozone and nitrogen dioxide, may have their origins in early life. http://bit.ly/33PClYN

Cite this article as: To T, Zhu J, Stieb D, et al. Early life exposure to air pollution and incidence of childhood asthma, allergic rhinitis and eczema. Eur Respir J 2020; 55: 1900913 [https://doi.org/10.1183/ 13993003.00913-2019].

\section{ABSTRACT}

Rationale: There is growing evidence that air pollution may contribute to the development of childhood asthma and other allergic diseases. In this follow-up of the Toronto Child Health Evaluation Questionnaire (T-CHEQ) study, we examined associations between early life exposures to air pollution and incidence of asthma, allergic rhinitis and eczema from birth through adolescence.

Methods: 1286 T-CHEQ participants were followed from birth until outcome (March 31, 2016) or loss to follow-up, with a mean of 17 years of follow-up. Concentrations of nitrogen dioxide $\left(\mathrm{NO}_{2}\right)$, ozone $\left(\mathrm{O}_{3}\right)$ and particulate matter with a 50\% cut-off aerodynamic diameter of $2.5 \mu \mathrm{m}\left(\mathrm{PM}_{2.5}\right)$ from January 1,1999 to December 31, 2012 were assigned to participants based on their postal codes at birth using ground observations, chemical/meteorological models, remote sensing and land-use regression models. Study outcomes included incidence of physician-diagnosed asthma, allergic rhinitis and eczema. Cox proportional hazard regression models were used to estimate hazard ratios per interquartile range of exposures and outcomes, adjusting for potential confounders.

Results: Hazard ratios of 1.17 (95\% CI 1.05-1.31) for asthma and 1.07 (95\% CI 0.99-1.15) for eczema were observed for total oxidants $\left(\mathrm{O}_{3}\right.$ and $\left.\mathrm{NO}_{2}\right)$ at birth. No significant increase in risk was found for $\mathrm{PM}_{2.5}$. Conclusions: Exposures to oxidant air pollutants $\left(\mathrm{O}_{3}\right.$ and $\left.\mathrm{NO}_{2}\right)$ but not $\mathrm{PM}_{2.5}$ were associated with an increased risk of incident asthma and eczema in children. This suggests that improving air quality may contribute to the prevention of asthma and other allergic disease in childhood and adolescence.

This article has supplementary material available from erj.ersjournals.com

Received: 7 May 2019 | Accepted after revision: 7 Nov 2019

The content of this work is copyright of the authors or their employers. Design and branding are copyright @ERS 2020.

This version is distributed under the terms of the Creative Commons Attribution Non-Commercial Licence 4.0. 


\section{Introduction}

Earlier studies have shown that immunological development and maturation starts during pregnancy and continues during early childhood [1]. Health risks from exposures at birth may serve as a surrogate indicator of exposures throughout pregnancy. Exposures during the first 3 years of life represent a critical period of immune development that may modify immune responses and cells, and thus influence the risk of allergies and other immune diseases later in life. Recent systematic reviews by KHREIs et al. [2] and BOWATTE et al. [3] suggested that childhood exposure to traffic-related air pollution (TRAP) contributes to the development of asthma. Assessing exposures both at birth and during early life is therefore important.

While a number of studies have examined the longitudinal association between childhood air pollution exposure and incidence of asthma or other allergic diseases [3-8], few have investigated this association into late adolescence. Furthermore, fewer have examined independent or concurrent associations with other environmental exposures such as greenness [9]. Thus, a gap in evidence exists on longitudinal studies of how air pollution may affect the development and persistence of new and prevalent cases of asthma and other allergic conditions (e.g. allergic rhinitis and eczema) in the adolescent population.

The Toronto Child Health Evaluation Questionnaire (T-CHEQ) study in Canada established a population-based cohort of 5619 grade 1 and 2 (aged 5-9 years) Toronto school children in 2006 using modified International Study of Asthma and Allergies in Childhood (ISAAC) methodology [10]. Parent-reported lifetime asthma prevalence in this population of Toronto children was high (16.1\%) [10]. This study reported that nitrogen dioxide $\left(\mathrm{NO}_{2}\right)$, a surrogate measure of TRAP exposure, was associated with the development and persistence of asthma in early childhood [11, 12]. In the 2006 T-CHEQ survey, participants were asked to provide permission/consent to use their unique Health Card Number (HCN) for data linkage in future research. The consented T-CHEQ participants who were born in Ontario were linked to the Ontario population-based health administrative databases. It has been suggested ozone $\left(\mathrm{O}_{3}\right)$ and $\mathrm{NO}_{2}$ can trigger an oxidative stress process in the lungs which can lead to cell death, inflammation, injury and loss of function [13]. Therefore, in addition to measuring the associations between individual air pollutant and disease risks, our current study also estimated the impact of these pollutants together as total oxidants. With this linked birth cohort, we aimed 1) to determine the incidence of asthma and other common allergic conditions (allergic rhinitis, eczema) in children through prospective follow-up from birth to adolescence, and 2) to examine the associations between air pollution and incidence of asthma and other allergic diseases.

\section{Methods}

Study population and data linkage

The original T-CHEQ study included 5619 grade 1 and 2 school children aged 5-9 years who were recruited in 2006 from 283 randomly sampled public schools in Toronto (ON, Canada) to participate in the survey. About half of the T-CHEQ participants $(n=2735(48.7 \%))$ gave consent to use their unique HCN for future data linkage, and 1286 of them were born in Ontario, were successfully linked to the Ontario Registered Persons Database housed at the Institute for Clinical Evaluative Sciences (ICES) and had complete data on all covariates. These children made up the T-CHEQ birth cohort for this study. More details can be found in the supplementary material.

\section{Measures}

Outcome measures

Children and youths were classified as having incident asthma by International Classification of Disease (ICD) codes (ICD-9: 493 and ICD-10: J45, J46) if they had: one or more asthma hospital admissions or two or more asthma Ontario Health Insurance Plan (OHIP) claims for physician services in 2 consecutive years (where the first claim is considered the diagnosis date). This case definition has been validated with 84\% sensitivity and 76\% specificity [14]. Allergic rhinitis (ICD-9: 477 and ICD-10: J301-J304) and eczema (ICD-9: 691.8 and ICD-10: L20) were identified by any physician health services claim for these conditions by their respective ICD codes. With the unique HCN, the T-CHEQ participants who met the inclusion criteria were traced back to their birth records to recreate the birth cohort for this study. All children in this study were followed prospectively from birth to their index date of outcomes of interest, death, end of study or loss to follow-up. The health administrative databases used in this study included the National Ambulatory Care Reporting System (emergency department visits), the Canadian Institute for Health Information Discharge Abstract Database (hospital admissions) and the OHIP Claims Database (physician outpatient claims), to capture health services use.

\section{Air pollution exposures}

The Ontario Registered Persons Database (RPDB) was used to compile the history of residential address of the birth cohort from birth to the end of the study. Given the peak incidence of asthma and other allergic 
disease in early childhood [15], we focused on air pollution exposures at baseline (birth) and early life (03 years of age). The exposures in the first 3 years of life were calculated based on all reported addresses during the first 3 years of life.

\section{Pollutants}

Particulate matter with a $50 \%$ cut-off aerodynamic diameter of $2.5 \mu \mathrm{m}\left(\mathrm{PM}_{2.5}\right)$ exposures were derived from total column aerosol depth retrievals from the Moderate Resolution Imaging Spectroradiometer (MODIS) that were related to near-surface $\mathrm{PM}_{2.5}$ using the GEOS-Chem chemical transport model and adjusted with local ground-based observations through geographically weighted regression [16]. $\mathrm{NO}_{2}$ exposures were estimated from a temporally adjusted national land-use regression model that combined National Air Pollution Surveillance (NAPS) fixed-site monitoring data, satellite $\mathrm{NO}_{2}$ estimates, road length within $10 \mathrm{~km}$, industrial land-use areas within various buffers and summer rainfall [17]. Ozone exposures were estimated for the months of May to October ( $8 \mathrm{~h}$ daily maximum) using a temporally adjusted model combining modelled $\mathrm{O}_{3}$ from the Canadian Hemispheric Regional Ozone and $\mathrm{NO}_{x}$ system (CHRONOS) operational regional air quality forecast model [18] with ground-based observations from monitors in Canada and the USA [19]. In addition to individual pollutants, we also employed total oxidants as a composite measure, with pollutant weights equivalent to their respective redox potentials (total oxidants= $\left.\left(\left(1.07 \times \mathrm{NO}_{2}\right)+\left(2.075 \times \mathrm{O}_{3}\right)\right) / 3.145\right)[20]$. Exposure surface concentrations of air pollution were then assigned to participants using the centroids of their postal codes at birth and cumulated from birth onwards. The $\mathrm{PM}_{2.5}$ estimates showed good agreement $\left(\mathrm{R}^{2}=0.82\right)$ with monitors over North America; the $\mathrm{NO}_{2}$ land-use regression model explained $74 \%$ of the variability in fixed-site monitoring concentrations and $43 \%$ of within-city $\mathrm{NO}_{2}$ concentrations from an independent dataset measured using Ogawa passive samplers in seven Canadian cities [17].

\section{Greenness}

The Normalised Difference Vegetation Index (NDVI) Landsat Time Series was used to measure greenness [16-19]. Annual NDVI metrics were linked to all six-digit DMTI Spatial single postal code locations and surrounding areas within $100 \mathrm{~m}$ [9]. NDVI values typically range from -1 to +1 , where -1 represents water, 0 corresponds to bare surfaces (e.g. rock, sand, rooftops and roads) and +1 represents healthy green vegetation [21]. The greenness data surfaces for Ontario from 1996 to 2015 were obtained from the Canadian Urban Environmental Health Research Consortium (CANUE) (https://canue.ca). More details can be found in the supplementary material.

\section{Covariates}

There were three domains of covariates collected by the 2006 T-CHEQ survey: child, parental/ demographic and home environmental factors. Child factors include age, sex, low birthweight $(<2500 \mathrm{~g})$, prematurity ( $<37$ weeks gestation), breastfeeding and enrolment in childcare. Parental/demographic factors include parental asthma and atopy, parental education level, and income adequacy. Home environmental factors include crowding (number of people living in household) and home exposures during first year of life (damp spots, use of gas to cook or heat, exposure to environmental tobacco smoke, pets, cockroaches and mould in the home). More details can be found in the supplementary material.

\section{Statistical analysis}

The number and proportion of children who developed asthma, allergic rhinitis or eczema were stratified by child, parental/demographic and home environmental factors to compare children who developed these outcomes of interest with those who did not. Chi-squared tests were used to assess differences in proportions by group where a p-value of $<0.05$ indicates a statistically significant difference. The relationship between outcomes of interest and exposure was examined using the Cox proportional hazards regression model. All hazard ratios were presented with $95 \%$ confidence intervals and were calculated per pollutant/NDVI interquartile range (IQR). The Cox proportional hazards regression models were repeated for exposures: at birth, averaged over the first 3 years of life and by three health outcomes (asthma, allergic rhinitis and eczema). All three domains of covariates (child, parental/demographic and home environmental factors) were included in the multivariable Cox proportional hazards regression models to adjust for potential confounding. Plots of the Martingale-based residuals were examined to check for evidence of violation of the proportional hazards assumption [22]. Covariates that did not meet the proportional hazards assumption were removed from the regression model. None of the covariates kept in the final Cox models violated the proportional hazards assumption.

We used Moran's $I$ to measure the overall spatial autocorrelation and to test for clustering of exposures and cases. Our Moran's I-values on air pollutants and cases were all $<0.2$ (close to 0 ) indicating no autocorrelation. 
We also modelled $\mathrm{NO}_{2}$ and $\mathrm{O}_{3}$ together as total oxidants, and examined the hazards of $\mathrm{PM}_{2.5}$ and outcomes stratifying by tertile of total oxidants [23], an approach suggested by WeICHENTHAL et al. [23], which showed that $\mathrm{PM}_{2.5}$ was associated with mortality in the highest tertile of the hazard ratios of oxidants but not in lower tertiles. All analyses were carried out using SAS Enterprise guide 6.1 (SAS Institute, Cary, NC, USA).

\section{Ethics approval}

Ethics approval for this study was obtained from the Hospital for Sick Children and Health Canada Research Ethics Boards (Toronto and Ottawa, ON, Canada, respectively). Individual informed study consent was received from each study participant's parent or guardian at the time of participation in the T-CHEQ survey, and permission was given for the HCN to be used for data linkage.

\section{Results}

1286 children were linked to birth records and health administrative databases using their unique HCN. They were born between 1996 and 2001, and were followed to March 31, 2016, for an average of 17 years.

\section{Descriptive statistics}

Figure 1 shows that among the 1286 children, 28.5\% had asthma ( $\mathrm{n}=366), 39.7 \%$ had allergic rhinitis $(\mathrm{n}=511)$ and $74.5 \%$ had eczema $(\mathrm{n}=958)$, while nearly $14 \%(\mathrm{n}=177)$ had all three conditions. Only $2.3 \%$ had asthma alone $(n=30)$ and $12.4 \%$ had asthma and either allergic rhinitis or eczema $(n=159)$. Table 1 compares child, parent/demographic and home environmental factors among children who had asthma, allergic rhinitis and eczema with those who did not. A higher proportion of children with asthma compared with children who did not have asthma were born with low birthweight $(9.0 \%$ versus $5.8 \%$; $\mathrm{p}=0.035)$, were male $(62.0 \%$ versus $49.2 \%$; $\mathrm{p}<0.001)$, were not breastfed $(11.5 \%$ versus $6.4 \% ; \mathrm{p}=0.002)$ and had a parental history of asthma $(28.7 \%$ versus $19.5 \%$; $<<0.001)$. Conversely, a lower proportion of children with asthma had pets in their home in the first year of life (31.1 versus $38.0 \%$; $\mathrm{p}=0.02)$. Similar patterns were observed comparing children with allergic rhinitis with those without and children with eczema with those without (table 1).

\section{Mean levels of exposures}

Table 2 shows the mean distributions of exposures to pollutants and greenness at birth and averaged over the first 3 years of life. The levels did not differ significantly between those with versus without asthma, allergic rhinitis or eczema. Furthermore, the mean levels of pollutants at birth did not differ significantly from those averaged over the first 3 years of life. Table 3 shows correlations among exposures. $\mathrm{O}_{3}$ and $\mathrm{NO}_{2}$ at birth were strongly negatively correlated, while $\mathrm{O}_{3}$ and $\mathrm{PM}_{2.5}$ at birth were moderately positively correlated, and $\mathrm{NO}_{2}$ and $\mathrm{PM}_{2.5}$ at birth were weakly negatively correlated. With the exception of $\mathrm{O}_{3}$ and $\mathrm{NO}_{2}$, correlations were weaker based on exposures over the first 3 years.

\begin{tabular}{lr}
\hline Asthma & \\
Asthma only & $30(2.3)$ \\
Asthma+allergic rhinitis & $28(2.2)$ \\
Asthma+eczema & $131(10.2)$ \\
Asthma+allergic rhinitis+eczema & $177(13.8)$ \\
Total asthma & $366(28.5)$ \\
Allergic rhinitis & \\
Allergic rhinitis only & $66(5.1)$ \\
Allergic rhinitis+asthma & $28(2.2)$ \\
Allergic rhinitis+eczema & $240(18.7)$ \\
Allergic rhinitis+asthma+eczema & $177(13.8)$ \\
Total allergic rhinitis & $511(39.7)$ \\
Eczema & \\
Eczema only & $410(31.9)$ \\
Eczema+asthma & $131(10.2)$ \\
Eczema+allergic rhinitis & $240(18.7)$ \\
Eczema+asthma+allergic rhinitis & $177(13.8)$ \\
Total eczema & $958(74.5)$
\end{tabular}

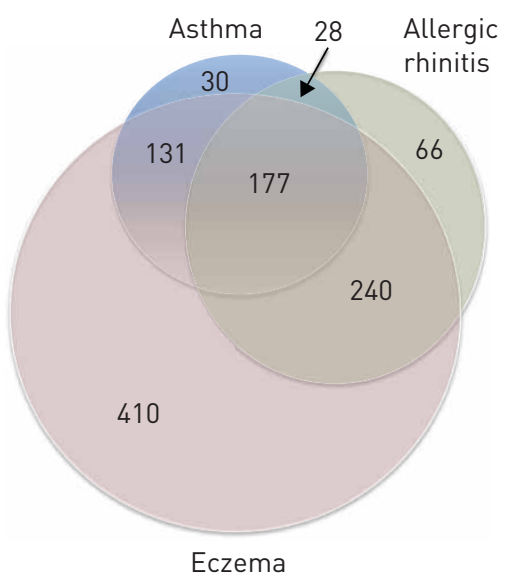

FIGURE 1 Distribution of asthma, allergic rhinitis and eczema in the study cohort. Data are presented as $\mathrm{n}(\%)$ or $\mathrm{n}$. Groups are not mutually exclusive. Percentages are calculated of the total. 
TABLE 1 Distribution of covariates by prevalence of asthma, allergic rhinitis and eczema in the study cohort

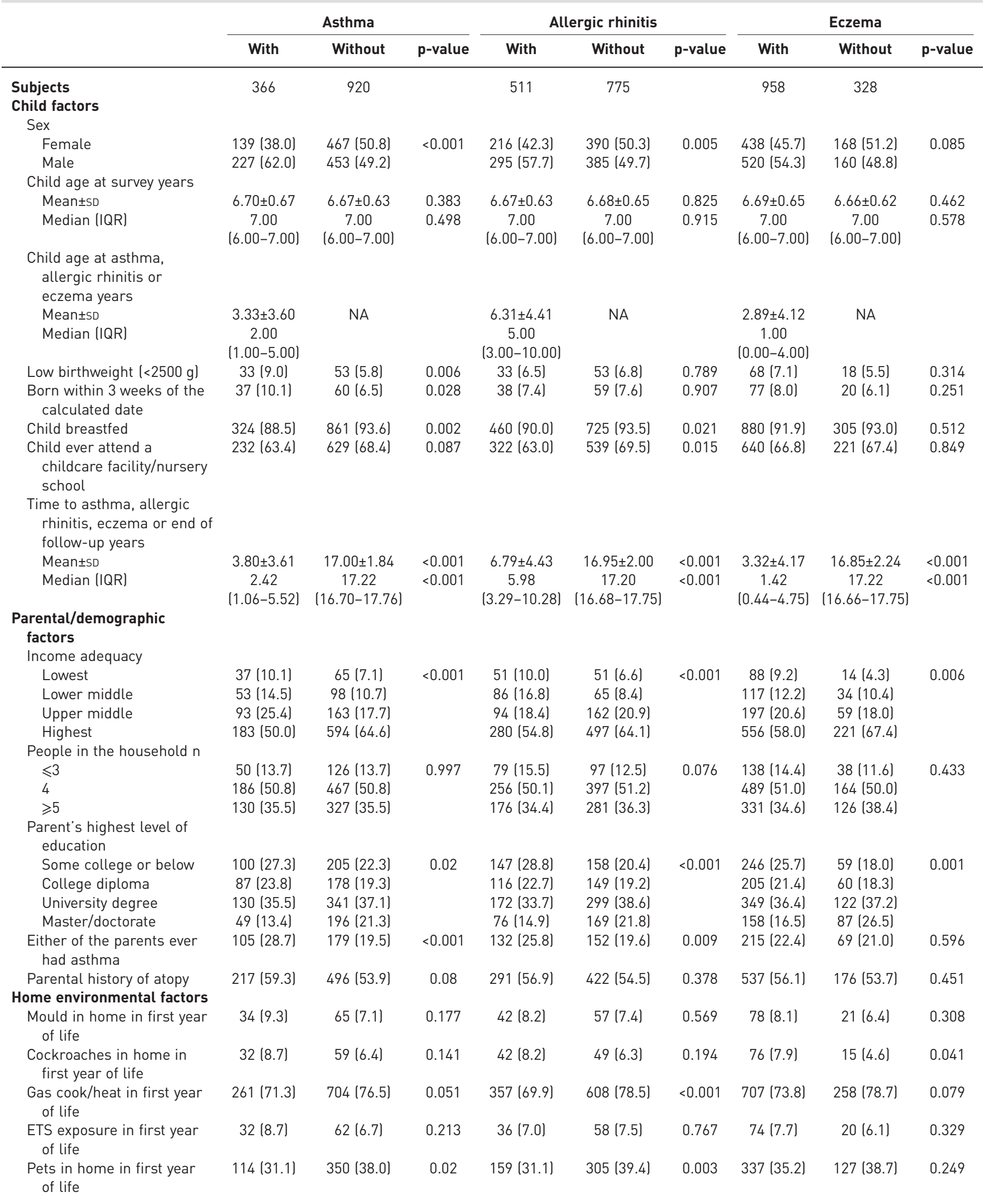

Data are presented as $\mathrm{n}(\%)$, unless otherwise stated. IQR: interquartile range; ETS: environmental tobacco smoke. 
TABLE 2 Mean distributions of exposures to air pollution and greenness at birth and averaged over the first 3 years of life

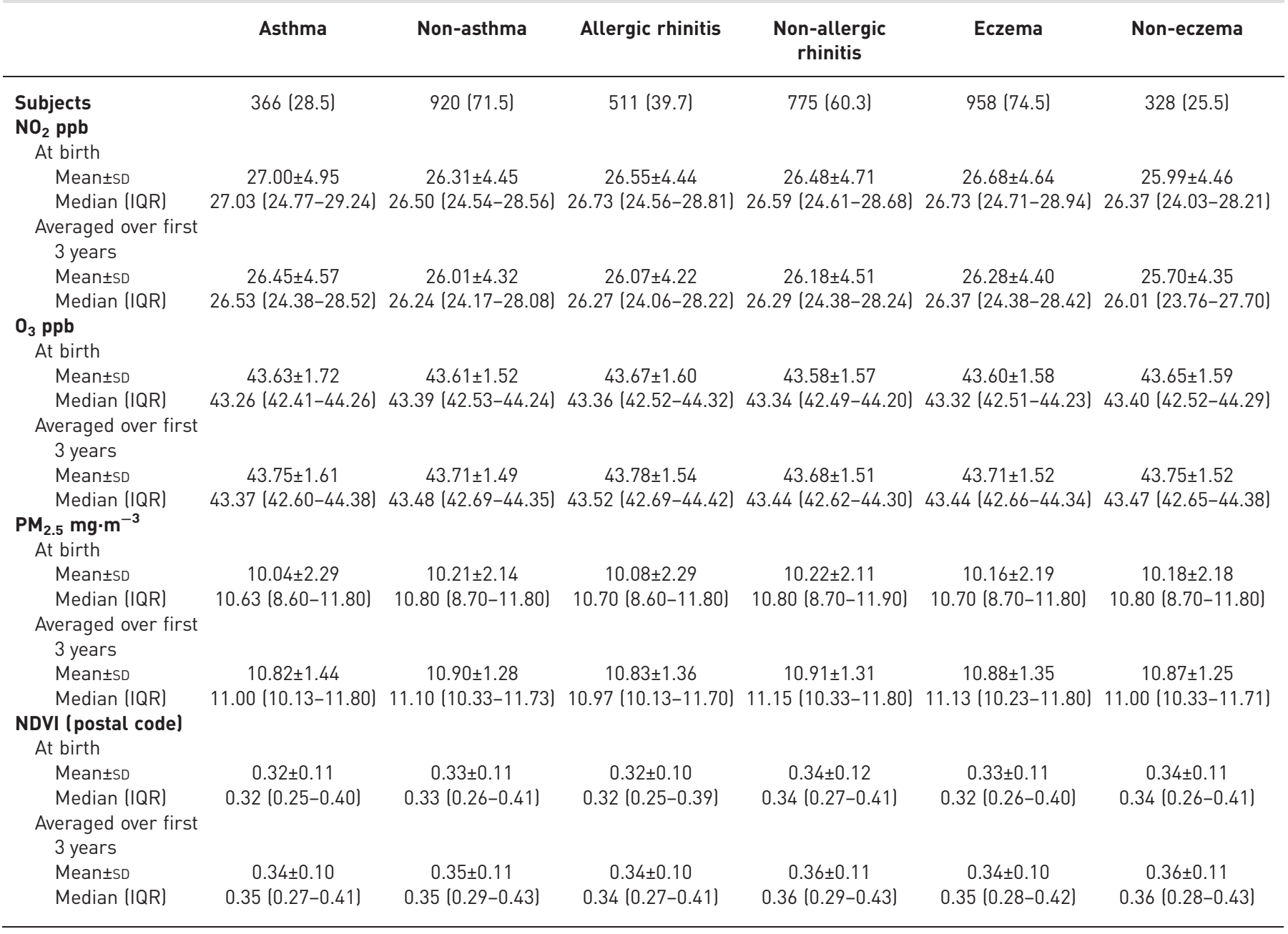

$\mathrm{NO}_{2}$ : nitrogen dioxide; IQR: interquartile range; $\mathrm{O}_{3}$ : ozone; $\mathrm{PM}_{2.5}$ : particulate matter with a $50 \%$ cut-off aerodynamic diameter of $2.5 \mu \mathrm{m}$; $\mathrm{NDVI}$ : Normalised Difference Vegetation Index.

\section{Hazard ratios from Cox regression models}

The results of single- and multi-pollutant adjusted Cox proportional hazards regression models are shown in table 4 and figure 2. All regression models were fully adjusted for child, parental/demographic and home environmental factors (detailed in the Methods section). Exposure to $\mathrm{O}_{3}$ at birth was not associated with asthma, allergic rhinitis or eczema in single-pollutant models, but a 1.2-fold higher risk of asthma (HR 1.22, 95\% CI 1.04-1.43) and allergic rhinitis (HR 1.15, 95\% CI 1.00-1.31) per IQR was observed adjusting for $\mathrm{NO}_{2}, \mathrm{PM}_{2.5}$ and NDVI in the multi-pollutant model. Exposure to $\mathrm{NO}_{2}$ at birth was more strongly associated with asthma and eczema in a multi-pollutant model also including $\mathrm{O}_{3}, \mathrm{PM}_{2.5}$ and NDVI (HR 1.17, 95\% CI 1.05-1.31 and HR 1.07, 95\% CI 0.99-1.15, respectively). In multi-pollutant models, exposures to $\mathrm{NO}_{2}$ and $\mathrm{O}_{3}$ in the first 3 years of life showed a similar trend of increasing the risk of asthma, allergic rhinitis and eczema. Total oxidants (the weighted sum of $\mathrm{NO}_{2}$ and $\mathrm{O}_{3}$ ) were associated with asthma and eczema in both single- (HR 1.14, 95\% CI 1.02-1.28 and HR 1.07, 95\% CI 1.00-1.15, respectively) and multi-pollutant models with $\mathrm{PM}_{2.5}$, NDVI and other covariates (HR 1.17, 95\% CI 1.051.31 and HR 1.07, 95\% CI $0.99-1.15$, respectively). We repeated the multi-pollutant regression model to examine the association stratified by age groups (onset of asthma $\leqslant 4$ and $>4$ years old). Results from the age-stratified analysis (table 5) showed that there was no difference in the hazard ratios by age at onset. The hazard ratios of $\mathrm{PM}_{2.5}$ and outcomes when stratified by tertile of total oxidants showed similar results to that of the multi-pollutant model of total oxidants and $\mathrm{PM}_{2.5}$ (supplementary material). Our results did not demonstrate a gradient effect of oxidants on $\mathrm{PM}_{2.5}$ and outcomes. 
TABLE 3 Correlations among exposure variables for the 1286 participants with complete covariate data

\begin{tabular}{|c|c|c|c|c|c|}
\hline & \multirow[t]{2}{*}{ Mean \pm sD } & \multicolumn{4}{|c|}{ Pearson correlation coefficient $r$} \\
\hline & & $\mathrm{NO}_{2}$ & $\mathbf{O}_{3}$ & $\mathrm{PM}_{2.5}$ & NDVI \\
\hline \multicolumn{6}{|l|}{$\mathrm{NO}_{2} \mathrm{ppb}$} \\
\hline Averaged over first 3 years & $26.14 \pm 4.40$ & & $-0.6220(p<0.0001)$ & $-0.0516(p=0.0648)$ & $-0.2055(p<0.0001)$ \\
\hline \multicolumn{6}{|l|}{$\mathrm{O}_{3} \mathrm{ppb}$} \\
\hline At birth & $43.61 \pm 1.58$ & & & $0.4442(p<0.0001)$ & $0.0060(p=0.8296)$ \\
\hline At birth & $10.16 \pm 2.19$ & & & & $-0.0810(p=0.0037)$ \\
\hline Averaged over first 3 years & $10.88 \pm 1.33$ & & & & $0.0114(p=0.6835)$ \\
\hline \multicolumn{6}{|l|}{ NDVI } \\
\hline At birth & $0.33 \pm 0.11$ & & & & \\
\hline Averaged over first 3 years & $0.35 \pm 0.11$ & & & & \\
\hline
\end{tabular}

$\mathrm{NO}_{2}$ : nitrogen dioxide; $\mathrm{O}_{3}$ : ozone; $\mathrm{PM}_{2.5}$ : particulate matter with a $50 \%$ cut-off aerodynamic diameter of $2.5 \mu \mathrm{m} ; \mathrm{NDVI}$ : Normalised Difference Vegetation Index.

\begin{abstract}
Discussion
This study represents the longest longitudinal study of the health of school-aged children in Canada with $>17$ years of follow-up. The lifetime incidence of asthma in the T-CHEQ cohort (28.5\%) was somewhat higher than our previous estimate using the same methods of case ascertainment of $22 \%$ by age 20 years based on Ontario-wide data from 1996 to 2007 [15], which could be attributable to differences between the T-CHEQ cohort and the Ontario population. We found a $17 \%$ increase in risk of developing asthma and $8 \%$ increase in risk of allergic rhinitis for each IQR increase in exposure to total oxidants $\left(\mathrm{O}_{3}\right.$ and $\mathrm{NO}_{2}$ ) at birth. Associations with $\mathrm{O}_{3}$ and $\mathrm{NO}_{2}$ in single- versus multi-pollutant models were less stable than
\end{abstract}

TABLE 4 Adjusted hazard ratios $(95 \% \mathrm{Cls}$ ) for asthma, allergic rhinitis, eczema and exposures at birth and over the first 3 years of life from single-pollutant, multi-pollutant and oxidants models

\begin{tabular}{|c|c|c|c|c|c|c|}
\hline & \multicolumn{2}{|c|}{ Asthma } & \multicolumn{2}{|c|}{ Allergic rhinitis } & \multicolumn{2}{|c|}{ Eczema } \\
\hline \multicolumn{7}{|c|}{ Single-pollutant model } \\
\hline $\mathrm{NO}_{2}$ & $1.09(0.99-1.20)$ & $1.06(0.96-1.16)$ & $0.97(0.90-1.05)$ & 0.94 (0.87-1.02) & $1.05(0.99-1.12)$ & $1.05(0.99-1.11)$ \\
\hline $\mathrm{O}_{3}$ & $1.01(0.90-1.14)$ & $1.02(0.90-1.14)$ & $1.07(0.98-1.18)$ & 1.08 (0.99-1.19) & $0.99(0.92-1.06)$ & $0.99(0.92-1.06)$ \\
\hline Oxidants $\#$ & $1.14(1.02-1.28)$ & $1.10(0.98-1.23)$ & $1.02(0.93-1.12)$ & $0.98(0.89-1.08)$ & $1.07(1.00-1.15)$ & $1.06(0.99-1.14)$ \\
\hline $\mathrm{PM}_{2.5}$ & $0.88(0.76-1.02)$ & $0.94(0.83-1.06)$ & $0.92(0.82-1.05)$ & $0.94(0.85-1.04)$ & $0.98(0.89-1.07)$ & $1.01(0.93-1.09)$ \\
\hline $\mathrm{NO}_{2}$ & $1.17(1.05-1.31)$ & $1.12(1.00-1.26)$ & $1.02(0.92-1.12)$ & $0.97(0.88-1.08)$ & $1.07(0.99-1.15)$ & $1.05(0.98-1.14)$ \\
\hline $\mathrm{O}_{3}$ & $1.22(1.04-1.43)$ & $1.13(0.97-1.31)$ & $1.15(1.00-1.31)$ & 1.07 (0.95-1.22) & $1.05(0.95-1.16)$ & $1.03(0.93-1.13)$ \\
\hline $\mathrm{PM}_{2.5}$ & $0.82(0.69-0.97)$ & $0.92(0.81-1.04)$ & $0.85(0.74-0.98)$ & $0.92(0.83-1.03)$ & $0.97(0.87-1.07)$ & $1.00(0.93-1.08)$ \\
\hline NDVI & $1.05(0.91-1.22)$ & $1.06(0.91-1.23)$ & $0.91(0.81-1.03)$ & $0.94(0.83-1.07)$ & $0.97(0.89-1.06)$ & $0.96(0.88-1.05)$ \\
\hline \multicolumn{7}{|c|}{$\begin{array}{l}\text { Oxidants model } \\
\text { (oxidants }{ }^{\#}+\mathrm{PM}_{2.5}+\mathrm{NDVI} \text { ) }\end{array}$} \\
\hline \multicolumn{7}{|c|}{$\begin{array}{l}\mathrm{NO}_{2} \text { : nitrogen dioxide; } \mathrm{O}_{3} \text { : ozone; } \mathrm{PM}_{2.5} \text { : particulate matter with a } 50 \% \text { cut-off aerodynamic diameter of } 2.5 \mu \mathrm{m} \text {; NDVI: Normalised Difference } \\
\text { Vegetation Index. Hazard ratios are calculated per interquartile range increase in exposure; all Cox models presented in the table met the } \\
\text { proportional hazard assumption according to the Schoenfeld residuals. Cox models for asthma and allergic rhinitis are adjusted for all } \\
\text { covariates: age, sex, parental education level, income adequacy, number of people in household, low birthweight, breastfeeding, enrolment in } \\
\text { childcare, whether child was born within } 3 \text { weeks of due date, home exposures during first year of life (damp spots, use of gas to cook or heat, } \\
\text { exposure to environmental tobacco smoke, pets, cockroaches and mould) and parental history of asthma and atopy. Covariates excluded in the } \\
\text { Cox models for eczema due to violation of the proportionality assumption: income adequacy, low birthweight, child was born within } 3 \text { weeks of } \\
\text { due date, breastfeeding, use of gas to cook or heat, parental history of asthma and atopy. " } \text { : oxidants }=\left(\left(1.07 \times \mathrm{NO}_{2}\right)+\left(2.075 \times \mathrm{O}_{3}\right)\right) / 3.145 \text {. }\end{array}$} \\
\hline
\end{tabular}



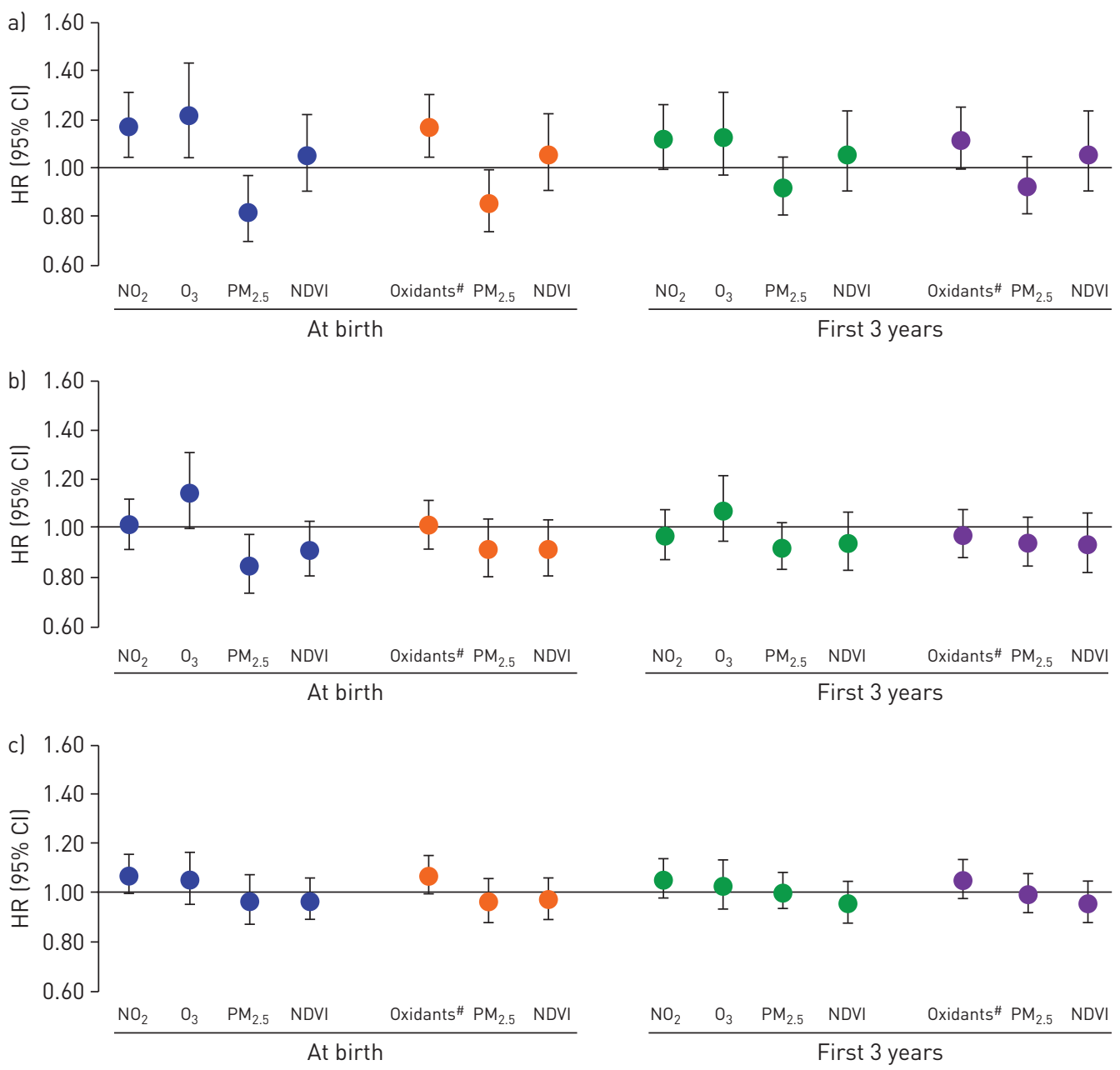

FIGURE 2 Forest plot of hazard ratios $(95 \%$ Cl) for a) asthma, b) allergic rhinitis and c) eczema by air pollutants and Normalised Difference Vegetation Index (NDVI) from multivariable multi-pollutant Cox regression models. ${ }^{\#}$ : oxidants $=\left(\left(1.07 \times \mathrm{NO}_{2}\right)+\left(2.075 \times \mathrm{O}_{3}\right)\right) / 3.145$.

for total oxidants, probably because of their strong negative correlation. These findings are important because they examined the effects of early life exposures to air pollution and their subsequent influence on health throughout childhood to adolescence.

Our study provides reliable exposure measurements as we compiled complete address histories from birth and assigned exposures according to residential address throughout those periods. Our results showed that the association of exposure and outcomes throughout early childhood is rather consistent. The point estimates of the hazard ratios at birth and those at the first 3 years differed by $<10 \%$ and the direction of the point estimates was consistent over time. The wider $95 \%$ confidence intervals of hazard ratios at the first 3 years could be partially attributable to a larger variance of exposures from year to year.

Exposures to ambient air pollutants including $\mathrm{O}_{3}, \mathrm{PM}_{2.5}$ and $\mathrm{NO}_{2}$ have been associated with worsening lung function and asthma symptoms in children [24-27]. Respiratory viruses and air pollutants such as $\mathrm{O}_{3}$ target the airway epithelium specifically as a means of entry to the underlying airways; when combined with an impaired ability to mount an antioxidant response, this results in an already susceptible airway epithelium that is more easily damaged [28]. WENDT et al. [29] used data from Texas in the USA between 2005 and 2007, a large population at high risk for asthma and living in an area with historically high $\mathrm{O}_{3}$ levels, to study the risk of incident asthma and $\mathrm{O}_{3}$. Similar to our study, Wend et al. [29] found a significant association of exposure to $\mathrm{O}_{3}$ and incident asthma in children.

Our birth cohort study did not find a positive association of early life exposure to $\mathrm{PM}_{2.5}$ and risks of developing childhood respiratory or allergic conditions. This lack of association might reflect weak or partially unresolved spatial gradients across the study area. YANG et al. [30] used the Netherlands Prevention and Incidence of Asthma and Mite Allergy (PIAMA) birth cohort data to measure the 
TABLE 5 Adjusted hazard ratios for asthma and exposures at birth from multi-pollutant models stratified by age groups (onset of asthma $\leqslant 4$ and $>4$ years old).

\begin{tabular}{lcc} 
& \multicolumn{2}{c}{ Asthma onset } \\
\cline { 2 - 3 } & $\leqslant 4$ years & >4 years \\
\hline $\begin{array}{l}\text { Subjects } \\
\text { Multi-pollutant model }\left(\mathbf{N O}_{\mathbf{2}}+\mathbf{O}_{\mathbf{3}}+\mathbf{P M}_{\mathbf{2 . 5}} \mathbf{+ N D V I )}\right.\end{array}$ & 258 & 108 \\
$\mathrm{NO}_{2}$ & $1.19(1.04-1.36)$ & $1.19(0.96-1.46)$ \\
$\mathrm{O}_{3}$ & $1.23(1.02-1.49)$ & $1.24(0.91-1.68)$ \\
$\mathrm{PM}_{2.5}$ & $0.82(0.67-1.01)$ & $0.80(0.59-1.09)$ \\
$\mathrm{NDVI}$ & $1.05(0.88-1.25)$ & $1.10(0.83-1.44)$ \\
\hline
\end{tabular}

Data are presented as $\mathrm{n}$ or $\mathrm{HR}(95 \% \mathrm{Cl})$. $\mathrm{NO}_{2}$ : nitrogen dioxide; $\mathrm{O}_{3}$ : ozone; $\mathrm{PM}_{2.5}$ : particulate matter with a $50 \%$ cut-off aerodynamic diameter of $2.5 \mu \mathrm{m}$; NDVI: Normalised Difference Vegetation Index. Hazard ratios are calculated per interquartile range increase in exposure; all Cox models presented in the table met the proportional hazard assumption according to the Schoenfeld residuals. Cox models for asthma are adjusted for all covariates: age, sex, parental education level, income adequacy, number of people in household, low birthweight, breastfeeding, enrolment in childcare, whether child was born within 3 weeks of due date, home exposures during first year of life ldamp spots, use of gas to cook or heat, exposure to environmental tobacco smoke, pets, cockroaches and mould) and parental history of asthma and atopy.

associations of long-term exposure to oxidative potential with respiratory health in 3701 children until they turned 12-14 years of age. Our risk estimates of exposure to $\mathrm{NO}_{2}$ and asthma and rhinitis are consistent with those YANG et al. [30] reported in the PIAMA birth cohort. They also did not find a significant association between respiratory health and $\mathrm{PM}_{2.5}$ mass.

GeHring et al. [31] used a combined cohort of 14126 participants from four prospective birth cohort studies from Germany, Sweden and the Netherlands to measure the longitudinal associations between exposure to air pollution and development of asthma and rhinoconjunctivitis throughout childhood and adolescence. This multiple birth cohort study found that the risk of incident asthma up to age 14-16 years increased with increasing exposure to $\mathrm{NO}_{2}$ and $\mathrm{PM}_{2.5}$ at the birth address, and suggested that exposure to air pollution early in life might contribute to the development of asthma throughout childhood and adolescence. Gehring et al.'s [31] estimates of risk of asthma and $\mathrm{NO}_{2}$ are consistent with our findings.

BOwATTE et al. [3] conducted a systematic review and meta-analysis that included 19 studies, 11 of which were birth cohort studies, from the late 1990s to 2014. While there was a wide variability in the odd ratios across studies, the point estimates of $\mathrm{NO}_{2}$ at age 1, 2, 3, 4 and 6 years were consistent with ours in the single-pollutant model. The results of this study highlighted that early childhood exposure to TRAP from birth to 5 years of age was associated with new onset of asthma throughout childhood and there was evidence to suggest that TRAP exposure may have an ongoing effect with a lag time of $\sim 3$ years [3].

KHREIS et al. [2] published a systematic review in 2017 and included 21 studies in their quantitative analyses. Our overall estimate of risk of $\mathrm{NO}_{2}$ and asthma was consistent with their finding that increase in exposure to $\mathrm{NO}_{2}$ in early childhood increases the risk of asthma. However, while KHREIS et al. [2] suggested an overall increase in risk of exposure to $\mathrm{PM}_{2.5}$ and asthma, we did not find an independent increase in risk of early life exposure to $\mathrm{PM}_{2.5}$ and asthma in our multi-pollutant model. KHREIS et al. [2] concluded that based on their meta-analysis, they supported the hypothesis that childhood exposure to TRAP contributes to the development of asthma.

Recent studies suggested that residential greenness may play a role in the aetiology of allergic respiratory diseases. However, the literature has been inconsistent, with some reporting protective effects $[9,32]$ and others suggesting that trees along roadsides can trap air pollution, decrease the air quality in the immediate vicinity [33] and therefore may pose a negative impact on health [32, 34]. The recent systematic reviews and meta-analysis conducted by LAMBERT et al. [35, 36] assessed the role of residential greenness on allergic respiratory diseases in children and adolescents. The results of the meta-analysis showed no significant overall association between residential greenness and asthma or allergic rhinitis. Similarly, our study did not find significant associations with exposure to residential greenness and allergic respiratory diseases.

It is well established that short-term exposure to air pollution can decrease lung function, exacerbate asthma, increase the risk of respiratory infections, and contribute to hospitalisation and mortality [37], and it has been reported that long-term exposure can lead to disease progression, such as from asthma to 
chronic obstructive pulmonary disease [38, 39]. Meta-analyses of 18-41 primary studies have consistently reported significant positive pooled estimates of the association between $\mathrm{NO}_{2}$ and asthma prevalence and/ or incidence, while associations with particulate matter were less consistent [2, 3, 5, 40]. A recent systematic review of ozone and asthma incidence reported that findings were inconsistent among 11 primary studies [41]. Our T-CHEQ Birth Cohort Study has a 17-year follow-up, which allowed us to study exposures to air pollution from birth and in early life, and to quantify their long-term subsequent risks of development of common childhood respiratory and allergic conditions such as asthma, allergic rhinitis and eczema. Some studies have suggested that ozone depletes antioxidant activity and increases indications of inflammation in the respiratory tract fluid lining and affects lung growth $[42,43]$. Short-term exposure to ozone can decrease lung function and increase the risk of respiratory infections in children. Children are at a higher risk because their lungs and other respiratory organs are smaller, and their immune, metabolism and detoxification systems are not well developed [44, 45]. Our observed elevated risks for asthma and allergic rhinitis associated with exposure to ozone, and eczema to nitrogen dioxide, imply that the adverse impacts of exposure to air pollutants, particularly to ozone and nitrogen dioxide, may have their origins in early life.

This study has several strengths, including the use of a birth cohort design with 17 years of follow-up with complete data on the residential history (home address) of every child. Data were linked to population health administrative databases to ascertain physician-diagnosed (instead of self or parental report) incidence of asthma, allergic rhinitis and eczema. The study is also strengthened by adjustment for a multitude of potential confounding risk factors including child, parental/demographic and home environmental factors. Additionally, although survey questions in which respondents are asked to recall events/behaviours in the past may be subject to potential recall bias, recall bias did not seem to be substantial in this study. For example, none of the home environment variables in the first year of life were significantly different in prevalence between children with or without asthma or eczema. Despite these strengths, a few limitations should be noted. Firstly, exposures in this study were assigned based on concentrations of air pollution estimated for place of residence. Therefore, misclassification (over- or under-estimation) of exposures is possible. Despite the small sample size, the study has sufficient statistical power to detect the effects of $\mathrm{NO}_{2}$ and $\mathrm{O}_{3}$ on asthma, $\mathrm{O}_{3}$ on allergic rhinitis, and $\mathrm{NO}_{2}$ on eczema in the multi-pollutant and multi-covariate adjusted model. However, it is a limitation that we may not have sufficient statistical power to measure smaller effects of pollutants on some of the outcomes. Additionally, we did not have data on the incidence of conditions by month to permit analysis by seasons or data to differentiate asthma types such as atopic and non-atopic asthma. Lastly, while we have adjusted for many potential confounding risk factors, residual confounding may still exist in relation to unmeasured confounders. Future research should explore spatiotemporal correlation between pollutants and how they may be influenced by meteorological factors such as wind speed and relative humidity.

In conclusion, this birth cohort study adds evidence of associations between early life exposure to air pollutants and risks of major respiratory and allergic conditions in young children. Improving air quality and providing advice on reducing air pollution exposure especially to $\mathrm{O}_{3}$ and $\mathrm{NO}_{2}$ may contribute to the prevention of asthma and other allergic disease in childhood and adolescence.

Acknowledgements: Health administrative data were provided by the Institute for Clinical Evaluative Sciences (ICES). However, ICES did not have any role in study design, analysis, interpretation of data or writing of the report. The opinions, results and conclusions presented in this report are those of the authors and are independent from the funding sources. No endorsement by ICES is intended or should be inferred. The air pollution data were provided by Statistics Canada and the NDVI metrics, indexed to DMTI Spatial Inc. postal codes, were provided by CANUE (Canadian Urban Environmental Health Research Consortium). Landsat 5 and Landsat 8 TOA data and greenest pixel data were provided by the US Geological Survey and Google, respectively, both via Google Earth Engine.

Author contributions: T. To and D. Stieb initiated and designed the study, interpreted findings and drafted the manuscript. J. Zhu conducted all statistical analysis. N. Gray and I. Fong conducted a search of the literature, summarised relevant study findings and reviewed the manuscript. S. Dell and M. Jerrett interpreted findings, reviewed and commented on drafts. L. Pinault carried out the annual adjustments to air pollution surfaces and mapped them to postal codes. A. Robichaud, R. Menard and J.R. Brook created the ozone surface, A. van Donkelaar and R.V. Martin created the particulate matter surface, and P. Hystad created the nitrogen dioxide surface. All authors have seen and approved the final version.

Conflict of interest: T. To has nothing to disclose. J. Zhu has nothing to disclose. D. Stieb has nothing to disclose. N. Gray has nothing to disclose. I. Fong has nothing to disclose. L. Pinault has nothing to disclose. M. Jerrett reports grants from Health Canada, during the conduct of the study. A. Robichaud has nothing to disclose. R. Ménard has nothing to disclose. A. van Donkelaar has nothing to disclose. R.V. Martin reports grants from Health Canada, during the conduct of the study. P. Hystad has nothing to disclose. J.R. Brook has nothing to disclose. S. Dell has nothing to disclose.

Support statement: This study was funded by Health Canada (contract HT421-163216/001/SS). Funding information for this article has been deposited with the Crossref Funder Registry. 


\section{References}

1 Martikainen MV, Ronkko TJ, Schaub B, et al. Integrating farm and air pollution studies in search for immunoregulatory mechanisms operating in protective and high-risk environments. Pediatr Allergy Immunol 2018; 29: 815-822

2 Khreis H, Kelly C, Tate J, et al. Exposure to traffic-related air pollution and risk of development of childhood asthma: a systematic review and meta-analysis. Environ Int 2017; 100: 1-31.

3 Bowatte G, Lodge C, Lowe AJ, et al. The influence of childhood traffic-related air pollution exposure on asthma, allergy and sensitization: a systematic review and a meta-analysis of birth cohort studies. Allergy 2015; 70: 245-256.

4 Fuertes E, Standl M, Cyrys J, et al. A longitudinal analysis of associations between traffic-related air pollution with asthma, allergies and sensitization in the GINIplus and LISAplus birth cohorts. PeerJ 2013; 1: e193.

5 Gasana J, Dillikar D, Mendy A, et al. Motor vehicle air pollution and asthma in children: a meta-analysis. Environ Res 2012; 117: 36-45.

6 Takenoue Y, Kaneko T, Miyamae T, et al. Influence of outdoor $\mathrm{NO}_{2}$ exposure on asthma in childhood: meta-analysis. Pediatr Int 2012; 54: 762-769.

7 Anderson HR, Butland BK, van Donkelaar A, et al. Satellite-based estimates of ambient air pollution and global variations in childhood asthma prevalence. Environ Health Perspect 2012; 120: 1333-1339.

8 Hasunuma H, Sato T, Iwata T, et al. Association between traffic-related air pollution and asthma in preschool children in a national Japanese nested case-control study. BMJ Open 2016; 6: e010410.

9 Sbihi H, Tamburic L, Koehoorn M, et al. Greenness and incident childhood asthma: a 10-year follow-up in a population-based birth cohort. Am J Respir Crit Care Med 2015; 192: 1131-1133.

10 Dell SD, Foty RG, Gilbert NL, et al. Asthma and allergic disease prevalence in a diverse sample of Toronto school children: results from the Toronto Child Health Evaluation Questionnaire (T-CHEQ) Study. Can Respir J 2010; 17: e1-e6.

11 Dell SD, Jerrett M, Beckerman B, et al. Presence of other allergic disease modifies the effect of early childhood traffic-related air pollution exposure on asthma prevalence. Environ Int 2014; 65: 83-92.

12 Shankardass K, Jerrett M, Dell SD, et al. Spatial analysis of exposure to traffic-related air pollution at birth and childhood atopic asthma in Toronto, Ontario. Health Place 2015; 34: 287-295.

13 Lodovici M, Bigagli E. Oxidative stress and air pollution exposure. J Toxicol 2011; 2011: 487074.

14 Gershon AS, Wang C, Guan J, et al. Identifying patients with physician diagnosed asthma in health administrative databases. Can Respir J 2009; 16: 183-188.

15 To T, Wang C, Guan J, et al. What is the lifetime risk of physician-diagnosed asthma in Ontario, Canada? Am J Respir Crit Care Med 2010; 181: 337-343.

16 van Donkelaar A, Martin RV, Spurr RJ, et al. High-resolution satellite-derived $\mathrm{PM}_{2.5}$ from optimal estimation and geographically weighted regression over North America. Environ Sci Technol 2015; 49: 10482-10491.

17 Hystad P, Setton E, Cervantes A, et al. Creating national air pollution models for population exposure assessment in Canada. Environ Health Perspect 2011; 119: 1123-1129.

18 Pudykiewicz J, Kallaur A, Smolarkiewicz P. Semi-Lagrangian modelling of tropospheric ozone. Tellus B 1997; 49: 231-248.

19 Robichaud A, Menard R, Zaitseva Y, et al. Multi-pollutant surface objective analyses and mapping of air quality health index over North America. Air Qual Atmos Health 2016; 9: 743-759.

20 Bratsch SG. Standard electrode potentials and temperature coefficients in water at 298.15 K. J Phys Chem Ref Data 1989; 18: 1-21.

21 Weier J, Herring D. Measuring vegetation (NDVI \& EVI). 2000. http://earthobservatory.nasa.gov/Features/ MeasuringVegetation Date last accessed: February 20, 2019.

22 Lin D, Wei LJ, Ying Z. Checking the Cox model with cumulative sums of Martingale-based residuals. Biometrika 1993; 80: 557-572.

23 Weichenthal S, Pinault LL, Burnett RT. Impact of oxidant gases on the relationship between outdoor fine particulate air pollution and nonaccidental, cardiovascular, and respiratory mortality. Sci Rep 2017; 7: 16401.

24 Akinbami LJ, Lynch CD, Parker JD, et al. The association between childhood asthma prevalence and monitored air pollutants in metropolitan areas, United States, 2001-2004. Environ Res 2010; 110: 294-301.

25 Babin S, Burkom H, Holtry R, et al. Medicaid patient asthma-related acute care visits and their associations with ozone and particulates in Washington, DC, from 1994-2005. Int J Environ Health Res 2008; 18: 209-221.

26 Lewis TC, Robins TG, Dvonch JT, et al. Air pollution-associated changes in lung function among asthmatic children in Detroit. Environ Health Perspect 2005; 113: 1068-1075.

27 O'Connor GT, Neas L, Vaughn B, et al. Acute respiratory health effects of air pollution on children with asthma in US inner cities. J Allergy Clin Immunol 2008; 121: 1133-1139.

28 Papadopoulos NG, Arakawa H, Carlsen KH, et al. International consensus on (ICON) pediatric asthma. Allergy 2012; 67: 976-997.

29 Wendt JK, Symanski E, Stock TH, et al. Association of short-term increases in ambient air pollution and timing of initial asthma diagnosis among Medicaid-enrolled children in a metropolitan area. Environ Res 2014; 131: 50-58.

30 Yang A, Janssen NA, Brunekreef B, et al. Children's respiratory health and oxidative potential of PM ${ }_{2.5}$ : the PIAMA birth cohort study. Occup Environ Med 2016; 73: 154-160.

31 Gehring U, Wijga AH, Hoek G, et al. Exposure to air pollution and development of asthma and rhinoconjunctivitis throughout childhood and adolescence: a population-based birth cohort study. Lancet Respir Med 2015; 3: 933-942

32 Lovasi GS, O’Neil-Dunne JP, Lu JW, et al. Urban tree canopy and asthma, wheeze, rhinitis, and allergic sensitization to tree pollen in a New York City birth cohort. Environ Health Perspect 2013; 121: 494-500.

33 Vos PE, Maiheu B, Vankerkom J, et al. Improving local air quality in cities: to tree or not to tree? Environ Pollut 2013; 183: 113-122.

34 Andrusaityte S, Grazuleviciene R, Kudzyte J, et al. Associations between neighbourhood greenness and asthma in preschool children in Kaunas, Lithuania: a case-control study. BMJ Open 2016; 6: e010341.

35 Lambert KA, Bowatte G, Tham R, et al. Greenspace and atopic sensitization in children and adolescents - a systematic review. Int J Environ Res Public Health 2018; 15. 
36 Lambert KA, Bowatte G, Tham R, et al. Residential greenness and allergic respiratory diseases in children and adolescents - a systematic review and meta-analysis. Environ Res 2017; 159: 212-221.

37 Thurston GD, Kipen H, Annesi-Maesano I, et al. A joint ERS/ATS policy statement: what constitutes an adverse health effect of air pollution? An analytical framework. Eur Respir J 2017; 49: 1600419.

38 To T, Zhu J, Larsen K, et al. Progression from asthma to chronic obstructive pulmonary disease. Is air pollution a risk factor? Am J Respir Crit Care Med 2016; 194: 429-438.

39 To T, Zhu J, Gray N, et al. Asthma and COPD overlap in women: incidence and risk factors. Ann Am Thorac Soc 2018; 15: 1304-1310.

40 Favarato G, Anderson HR, Atkinson R, et al. Traffic-related pollution and asthma prevalence in children. Quantification of associations with nitrogen dioxide. Air Qual Atmos Health 2014; 7: 459-466.

$41 \mathrm{Zu} \mathrm{K}$, Shi L, Prueitt RL, et al. Critical review of long-term ozone exposure and asthma development. Inhal Toxicol 2018; 30: 99-113.

42 Behndig AF, Blomberg A, Helleday R, et al. Antioxidant responses to acute ozone challenge in the healthy human airway. Inhal Toxicol 2009; 21: 933-942.

43 World Health Organization. Ambient Air Pollution: A Global Assessment of Exposure and Burden of Disease. Geneva, WHO, 2016.

44 Sacks JD, Stanek LW, Luben TJ, et al. Particulate matter-induced health effects: who is susceptible? Environ Health Perspect 2011; 119: 446-454.

45 Vinikoor-Imler LC, Owens EO, Nichols JL, et al. Evaluating potential response-modifying factors for associations between ozone and health outcomes: a weight-of-evidence approach. Environ Health Perspect 2014; 122: $1166-1176$ 